\title{
Ureteroscopic Pneumatic Lithotripsy of Impacted Ureteral Calculi
}

\author{
Artur H. Brito, Anuar I. Mitre, Miguel Srougi \\ Division of Urology, School of Medicine, University of Sao Paulo, Sao Paulo, SP, Brazil
}

\begin{abstract}
Introduction: This work evaluates the results of ureteroscopic treatment of impacted ureteral stones with a pneumatic lithotripter.

Materials and Methods: From March 1997 to May 2002, 42 patients with impacted ureteral stones were treated by retrograde ureteroscopic pneumatic lithotripsy. Twenty-eight patients were female and 14 were male. The stone size ranged from 5 to $20 \mathrm{~mm}$. The ureteral sites of the stones were distal in 21, middle in 12 and proximal in 9.

Results: Considering stones with distal location in the ureter, 1 patient had ureteral perforation and developed a stricture in the follow-up (4.7\%). As for stones in the middle ureter, 2 perforations and 1 stricture were observed (8.3\%) and regarding stones located in the proximal ureter, 5 perforations and 4 strictures occurred (44\%). In the mid ureter, 1 ureteral avulsion was verified. In 34 patients without ureteral perforation, only 1 developed a stricture (2.9\%). Of 8 patients who had perforation, 6 developed strictures. The overall incidence of stricture following treatment of impacted ureteral calculi was $14.2 \%$

Conclusions: Ureteroscopy for impacted ureteral calculi is associated with a higher incidence of ureteral perforation and stricture. Ureteroscopy of proximal ureteral calculi is associated with a high risk of perforation, when compared to mid or distal ureteral calculi. Ureteral perforation at the site of the stone seems to be the primary risk factor for stricture formation in these cases.
\end{abstract}

Key words: ureteroscopy; ureteral calculi; lithotripsy; injury; stenosis

Int Braz J Urol. 2006; 32: 295-9

\section{INTRODUCTION}

Impacted ureteral stone is commonly considered as a condition where a stone remains at the same site for more than 2 months (1). Impacted ureteral stone are the most difficult to treat, because there is a severe ureteral inflammation. This fact results in an increased risk of ureteral injury by instruments during endoscopic procedure (2). Extracorporeal shockwave lithotripsy (SWL) is widely used for treatment of ureteral stones as well as ureteroscopic techniques with a high rate of success $(3,4)$. However, poor results have been obtained with the treatment of impacted ureteral stones by SWL $(5,6)$. On the other hand, ureteroscopic approach is not so easy and has a high rate of complications (2). Although new ureteroscopes and lithotripters have been developed, the best treatment for impacted ureteral stones remains controversial. Ureteral stricture formation is a well recognized complication of impacted stone disease with rates as high as $5 \%$ after any treatment modality employed in early series (7). 
Harmon et al. reported the rate of stricture formation after ureteroscopy to be $0.5 \%$ in 1992 compared to $1.5 \% 10$ years earlier (8). In the present study, we assessed prospectively the effectiveness of ureteroscopic pneumatic lithotripsy for treatment of impacted ureteral stones.

\section{MATERIALS AND METHODS}

From March 1997 to May 2002, 42 patients with impacted ureteral stones were treated by ureteroscopic pneumatic lithotripsy. Twenty-eight patients were female and 14 were male. The age ranged from 23 to 72 years old. The stone size ranged between 5 and $20 \mathrm{~mm}$. One patient had a $5 \mathrm{~mm}$ calculus, 11 had calculi between 6 and $10 \mathrm{~mm}, 18$ had calculi between 11 and $15 \mathrm{~mm}$ and 12 patients had calculi between 16 and $20 \mathrm{~mm}$. Stones were located in the distal ureter in 21 patients, in the mid ureter in 12 and in the proximal ureter in 9 .

The access to the calculi was retrograde in all patients. The procedures were carried out with the patients in the lithotomy position under lumbar anesthesia. Ureteral orifice dilatation was necessary in 3 patients.

A retrograde ureteropyelogram was performed in all cases to study the ureteral anatomy and a guide wire (Teflon or hydrophilic) was inserted prior to the introduction of the ureteroscope. The hydrophilic guide wire was used in the cases where it was impossible to pass the Teflon guide wire.

Ureteroscopy was performed with $8.5 \mathrm{~F}$ semi rigid ureteroscope (Wolf Medical Instruments, Vernon Hills, Illinois, USA). The ureteroscope was introduced just under the stone and confirmation of its attachment to the edematous and hyperemic ureteral mucosa was obtained. The fragmentation of the stones was done with a pneumatic lithotripter (Electro Medical Systems, Kaufering, Germany). The fragments were removed with a grasping forceps or a Dormia basket. At the end of the procedure, a retrograde ureteropyelogram was performed to verify whether there was perforation and a double-J catheter was introduced in all the patients and left in place for 3 weeks (Figure-1). All the procedures were performed
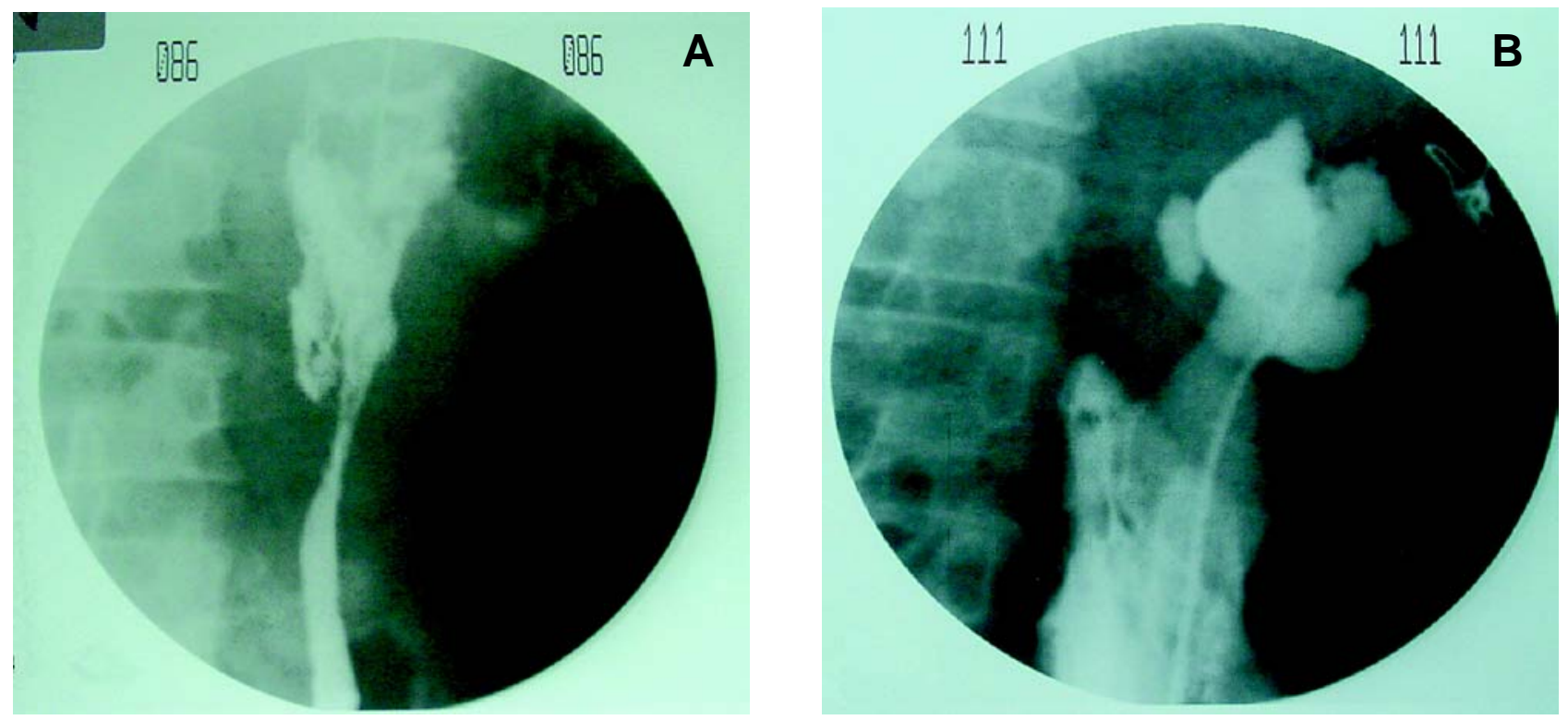

Figure 1 - Intraoperative proximal ureteral perforation (A) treated with double-J stenting (B). 
Table 1 - Stone size and incidence (percentage) of ureteral perforation.

\begin{tabular}{llll}
\hline Stone Size & Distal Ureter & Mid Ureter & Proximal Ureter \\
\hline$<5 \mathrm{~mm}$ & $\begin{array}{l}\text { Patients }=1 \\
\text { Perforation }=0\end{array}$ & $\begin{array}{l}\text { Patients }=0 \\
\text { Perforation }=0\end{array}$ & $\begin{array}{l}\text { Patients }=0 \\
\text { Perforation }=0\end{array}$ \\
$6-10 \mathrm{~mm}$ & $\begin{array}{l}\text { Patients }=8 \\
\text { Perforation }=0\end{array}$ & $\begin{array}{l}\text { Patients }=2 \\
\text { Avulsion }=1(50 \%)\end{array}$ & $\begin{array}{l}\text { Patients }=1 \\
\text { Perforation }=0\end{array}$ \\
& Patients $=4$ & Patients $=6$ & Patients $=8$ \\
$11-15 \mathrm{~mm}$ & Perforation $=0$ & Perforation $=0$ & Perforation $=5(62.5 \%)$ \\
& Patients $=9$ & Patients $=3$ & Patients $=0$ \\
$16-20 \mathrm{~mm}$ & Perforation $=1(11.1 \%)$ & Perforation $=2(66.6 \%)$ & Perforation $=0$ \\
\end{tabular}

under fluoroscopic and visual guidance. All patients were submitted to an intravenous pyelogram after 2 months to verify ureteral patency.

\section{RESULTS}

No complication was observed for stone smaller than $5 \mathrm{~mm}$. For the 11 stones between 6 and $10 \mathrm{~mm}$, there was 1 ureteral avulsion with the Dormia basket. This complication was treated by ureteral reimplantation with a Boari bladder flap. Postoperative evaluation at 6 months, by intravenous pyelogram, showed a good result. For the 18 calculi between 11 and $15 \mathrm{~mm}$ there were 5 ureteral perforations and for the 12 calculi between 16 and $20 \mathrm{~mm}$, there were 3 cases of ureteral perforation (Table-1).

The relation of the calculi site and perforation showed that in 21 distal calculi there were only 1 perforation and 1 stricture $(4.7 \%)$. In the 12 mid ureteral calculi, there were 1 ureteral avulsion, 2 perforations and 1 stricture $(8.3 \%$ ), and in the 9 proximal ureteral calculi, there were 5 perforations and 4 strictures $(44 \%)$. In 3 of these 4 patients that developed strictures, it was not possible to withdraw all fragments, because during the procedure there has been a mild hemorrhage and it was stopped (Table-2).

The overall incidence of strictures was $14.2 \%$. For the treatment of ureteral strictures, the renal function was also available in 4 patients that presented large pelvicaliceal dilation. In these patients, a nephrostomy tube was placed and a renal scintigraphy was done. In 3 patients, renal scintigraphy shows a renal function lower than $20 \%$, being indicated nephrectomy for these cases and in 1 patient the renal function was higher than $20 \%$ being indicated incision of the stenosis with the Acucise ${ }^{\circledR}$ catheter (Applied Urology, Rancho Santa Margarita,

Table 2 - Complications of impacted ureteral calculus.

\begin{tabular}{|c|c|c|c|c|}
\hline Calculus Site & & Distal Ureter & Mid Ureter & Proximal Ureter \\
\hline Patients & & 21 & 12 & 9 \\
\hline Complications & $\begin{array}{l}\text { Perforation } \\
\text { Avulsion }\end{array}$ & $\begin{array}{l}1(4.7 \%) \\
0\end{array}$ & $\begin{array}{l}2(16.6 \%) \\
1(11.1 \%)\end{array}$ & $\begin{array}{l}5(55.5 \%) \\
0\end{array}$ \\
\hline Stricture & & $1(4.7 \%)$ & $1(8.3 \%)$ & $4(44 \%)$ \\
\hline
\end{tabular}


California, USA). Three patients had ureteral stenosis with good renal function and an incision of the stenosis with the Acucise ${ }^{\circledR}$ catheter was indicated. Evaluation by intravenous pyelogram, at 6 months, of the 4 patients in that was did incision with Acucise $^{\circledR}$ catheter, showed good results in all.

Analysis of all cases of ureteral stricture showed that in 34 patients without ureteral perforation only one presented late stricture $(2.9 \%)$, while in 8 patients that had perforation, 6 presented strictures $(75 \%)$.

The overall stone free rate was $92.9 \%$.

\section{DISCUSSION}

SWL can be a modality treatment for most upper urinary tract stones, because of its simplicity, noninvasiveness and minimal morbidity. However, some stones are difficult to fragment by SWL or the fragments may remain in the urinary tract even after successful fragmentation of the stone. Since residual stones can cause hydronephrosis followed by a decrease in renal function or urinary tract infection, residual fragments should be removed even if they are less than $4 \mathrm{~mm}$ in diameter (9). Impacted ureteral calculi are more difficult to fragment with SWL than stones lying in the renal pelvis, because of the lack of natural expansion space for stones in ureter $(10,11)$. In the aforementioned situations, ureterolithotripsy is the best treatment option (12).

Four sources of energy for intracorporeal lithotripsy are now available, that is, electrohydraulic, ultrasound, pneumatic and Holmium laser. With electrohydraulic and ultrasonic energy, there is more risk of complication, as for example ureteral perforation. The pneumatic energy is strong enough for fragmenting all types of stones and is cheaper than Holmium laser. However, with the pneumatic lithotripter, there is more retrograde migration of the ureteral stone during its fragmentation.

Impacted ureteral stone, is considered a condition where a stone remains at the same site for more than 2 months (1). All cases in our series fulfilled this criterion and were treated by ureteroscopic pneumatic lithotripsy.
Migration of stone fragments to the kidney is an unfavorable aspect that may occur during pneumatic lithotripsy requiring special care during stone fragmentation (13). Removal of all the stone fragments is important to prevent additional chronic mucosal inflammation leading to stricture formation $(14,15)$.

Ureteral stricture formation is a recognized complication of ureteral instrumentation and stone removal. The mechanism of stricture formation has not yet been completely elucidated and it is likely to be multi-factorial. However, direct mechanical trauma (perforation or avulsion), relative ischemia from the use of large diameter ureteral instruments and thermal injury have been implicated as contributing factors in stricture formation (1).

Patients with chronically impacted stones, show inflammation and edema of the ureteral wall, and these changes may spread to the surrounding tissues. Histological studies have revealed chronic inflammation, interstitial fibrosis and urothelial hypertrophy at the site of impacted stones. Ureteral edema and fibrosis may arise from ischemia secondary to chronic pressure or from an immunological reaction to the stone material $(2,15)$.

Dretler \& Young identified residual stones as an etiological factor of ureteral stricture. They found foreign body reaction around calcium oxalate crystals, at the site of the stricture, in patients who underwent stone fragmentation before extraction. This finding suggests that fragments of calculi embedded in the ureteral mucosa may stimulate inflammation that may result in stricture formation (15).

After this study, we believe that large impacted ureteral stones, in the proximal ureter, should be treated by retroperitoneoscopy or flexible ureteroscope with Holmium laser stone-fragmentation and not with semi rigid ureteroscopic. In this study, we work only with semi rigid ureteroscopic and stone fragmentation with pneumatic lithotripter because we did not have flexible ureteroscope and Holmium laser by that time.

Our experience showed that when there was ureteral perforation during the extraction of impacted calculi, there was a higher risk of ureteral stricture formation. Although ureteral perforation can be 
avoided with meticulous technique, the luminal pathological changes increase odds of the injury and stricture formation.

\section{CONCLUSIONS}

Ureteroscopic pneumatic lithotripsy is a useful treatment modality of impacted ureteral calculi, but it is associated with a higher incidence of strictures. The treatment of proximal ureteral calculi has an increased risk of perforation, when compared to distal ureteral calculi, and ureteral perforation increases the risk of stricture formation.

\section{CONFLICT OF INTEREST}

None declared.

\section{REFERENCES}

1. Roberts WW, Cadeddu JA, Micali S, Kavoussi LR, Moore RG: Ureteral stricture formation after removal of impacted calculi. J Urol. 1998; 159: 723-6.

2. Morgentaler A, Bridge SS, Dretler SP: Management of the impacted ureteral calculus. J Urol. 1990; 143: 263-6.

3. Streem SB: Contemporary clinical practice of shock wave lithotripsy: a reevaluation of contraindications. J Urol. 1997; 157: 1197-203.

4. Erhard M, Salwen J, Bagley DH: Ureteroscopic removal of mid and proximal ureteral calculi. J Urol. 1996; 155: 38-42. Erratum in: J Urol 1996; 155: 1039.

5. Dretler SP, Keating MA, Riley J: An algorithm for the management of ureteral calculi. J Urol. 1986; 136: 1190-3.

6. Lingeman JE, Shirrell WL, Newman DM, Mosbaugh PG, Steele RE, Woods JR: Management of upper ureteral calculi with extracorporeal shock wave lithotripsy. J Urol. 1987; 138: 720-3.

7. Kramolowsky EV: Ureteral perforation during ureterorenoscopy: treatment and management. J Urol. 1987; 138: 36-8.

8. Harmon WJ, Sershon PD, Blute ML, Patterson DE, Segura JW: Ureteroscopy: current practice and longterm complications. J Urol. 1997; 157: 28-32.

9. Yagisawa T, Kobayashi C, Ishikawa N, Kobayashi H, Toma H: Benefits of ureteroscopic pneumatic lithotripsy for the treatment of impacted ureteral stones. J Endourol. 2001; 15: 697-9.

10. Mueller SC, Wilbert D, Thueroff JW, Alken P: Extracorporeal shock wave lithotripsy of ureteral stones: clinical experience and experimental findings. J Urol. 1986; 135: 831-4.

11. Chaussy CG, Fuchs GJ: Current state and future developments of noninvasive treatment of human urinary stones with extracorporeal shock wave lithotripsy. J Urol. 1989; 141: 782-9.

12. Biri H, Kupeli B, Isen K, Sinik Z, Karaoglan U, Bozkirli I: Treatment of lower ureteral stones: extracorporeal shockwave lithotripsy or intracorporeal lithotripsy? J Endourol. 1999; 13: 77-81.

13. Mitre AI, Chambo JL, Arap S: Ureteroscopy. In: Glenn's Urologic Surgery. Philadelphia, LippincottRaven Publishers. 1998; pp. 942-5.

14. Chambo JL, Mitre AI, El Hayek OR, Brito AH, Arap S: Experiencia com um novo tipo de litotridor intracorporeo: litotridor balistico-pneumatico Swiss Litoclast. J Bras Urol. 1996; 22: 68-70.

15. Dretler SP, Young RH: Stone granuloma: a cause of ureteral stricture. J Urol. 1993; 150: 1800-2.

\section{Correspondence address:}

Dr. Artur Henrique Brito

Rua Barata Ribeiro, 414 / 36

São Paulo, SP, 01308-000, Brazil

Fax: + 5511 3255-1044

E-mail: arturbrito@uol.com.br 